\title{
THE USE OF SOCIAL MEDIA IN EMPLOYER BRANDING IN THE LIGHT OF THE RESEARCH ON THE ICT SECTOR ENTERPRISES
}

\footnotetext{
ANNA SZWAJLIK

University of Szczecin, Faculty of Management and Economics of Services, POLAND

e-mail: anna.szwajlik@wzieu.pl

RECEIVED

ACCEPTED

JEL

CLASSIFICATION

KEYWORDS

ABSTRACT

10 December 2018

28 December 2018

Q31

employer branding, social media

This article, in its first part, presents a theory related to the creation of an employer and social media brand as a new group of tools supporting employer branding. The second part depicts the results of qualitative research carried out among ICT sector enterprises to illustrate the phenomenon described above. The aim of the article is to show the importance of social media in emploer branding. The research method used in the article are individual interviews carried out among managers of the ICT sector enterprise.
}

\section{Introduction}

In the last decade, employer branding has aroused interest of both the scientific community and business practitioners. The main reasons for this result from, inter alia, the intensification of competition between enterprises and thus the increase in the demand for talented and valuable employees. It should be noted that in dynamically developing sectors, such as ICT, there is a lack of specialists, hence acquisition of employees relevant for the 
company becomes an important goal of the organization. In response to the situation, many enterprises focus their activities on creating the right image of the employer, both among potential and existing employees. As part of communication channels and tools, social media is used more and more efficiently to create the company's brand as a desirable employer on the market.

The purpose of this article is to present the scope of using social media in creating the employer's image in the ICT sector. The author used in-depth individual interviews to collect opinions as well as verify the scope and functions of social media in employer branding.

\section{Roles and functions of social media in creating the image of an employer}

First attempts to investigate the relationship between the brand considered in terms of marketing and human resources management were undertaken by Ambler and Barrow. They defined employer branding as a package of functional, economic and psychological benefits provided by employment in a given enterprise and identified with the employing company (Ambler, Barrow, 1996, pp. 185-206).

K. Backhaus and S. Tikko underlined that it exposes unique aspects of working in a company, allows to distinguish an employer from others and is based on encouraging, motivating and maintaining the present employees and acquiring new ones (Backhaus, Tikko, 2004, pp. 501-517). These unique features of the employment offer, i.e. the package of benefits and values offered, are referred to as the Employer Value Proposition (Barrow, Mosley, 2005, pp. 86-89).

Various factors determine employer branding, including: sector attractiveness, company reputation, quality of products and services, location, work environment, pay, economic conditions, employee benefits, people and culture, balance between work and private life, social responsibility (Mehta, Sharma 2016, pp. 37-38). It is imperative that companies strengthen their image by working on each of the above factors and verify the perception of the brand among employees.

Organizations with strong employer branding derive benefits from it, the most important of which are (Mehta, Sharma, 2016, pp. 37-38):

1. Acquiring better quality candidates: organizations that can attract the best talents can gain an advantage over the competition (Harari, 1998, pp. 23-26). It is easier for such organizations to recruit qualified candidates, as such candidates understand and identify with the culture of the organization that makes them feel part of it.

2. Acquiring passive candidates: clearly articulated employer branding helps to attract candidates who do not want to actively change jobs but would consider a good opportunity if such was made available to them. A global survey conducted by the Corporate Leadership Council (CLC) in 2006 showed that effectively building employer's image allows organizations to have access to a deeper pool of talents.

3. Transition towards a psychological contract: a strong employer brand psychologically ties employees more tightly than a contract of employment. Such employees prefer to stay in the organization longer even if the circumstances lead to consideration of other employment opportunities. This lowers the employment turnover rate and the associated organizational costs.

4. Reducing recruitment costs: a convincing and well communicated message from the organization may lead candidates to ask for vacancies. The organization does not have to inform about vacancies or wait 
for applications, and at the same time it saves time and expenses related to the employment of new candidates.

5. Brand ambassadors: when employees accept their organization, they not only engage in its goals but also talk about it, giving good opinions to its peers, which helps in replenishing the talent pool.

6. Increased profitability: a strong employer brand attracts the best and most diverse talents increasing productivity and profitability.

Employer branding activities can be divided into two types: internal, directed to current employees of the company, and external. External employer branding are activities designed to shape the employer's brand in an environment whose participants are entities in direct relations with members of a given enterprise and potential new employees (Bednarska-Olejniczak, 2017, pp. 45-46). External employer branding can be divided into the image and recruitment categories. The first one focuses on creating an image of the company as an attractive employer, whereas the other on actions aimed at facilitating the company's acquisition of employees.

As literature on the subject indicates among companies that consciously create the employer's brand, there is an increasing interest in using social media, both in the recruitment process and creation of an experience environment for both employees and candidates.

A.M. Kaplan and M. Haenlei proposed the fullest definition of the concept of social media which treats social media as: a group of web-based application solutions that rely on the ideological and technological basis of Web 2.0 and which enable the creation and exchange of user-generated content (Kaplan, Haenlei, 2010, pp. 59-68). Another definition describes social media as media subject to social control, which can be used on any scale. It contains both the content of the message and possible points of view relating to information (Kaplan, Haenlei, 2010, pp. 59-68). The above definitions refer to the basic feature of social media, which is the maintenance of interpersonal relationships through mutual exchange of content. V. Vouri, deepening the subject of social media in her research, points to more specific features of social media which are (Vouri, 2011, pp. 59-66): interactivity, two-way communication, many-to-many communication, open channel, information democratization. Relating to the above, at the level of activities carried out in the enterprise, the use of social media allows for:

- engaging participants of internal and external environment in the co-creation process,

- publishing and sharing content online,

- connecting users and creating convenient conditions for interaction between them,

- completing content by adding a description or filtering information, marking content and showing connections between content,

- consolidating and matching content by attaching existing virtual content.

The features presented above, such as the scope of using social media, indicate their multifunctionality, identified as communicating, collaborating, connecting, completing, and combining (Vouri, 2011, pp. 59-66).

Communicating function can be understood as sharing opinions, storing and publishing content/image or audio. Its main communication channels include: blogs, websites, microblogs, forums, discussion groups, presentations. Examples of tools that perform the above function include: YouTube, Blogger, Twitter, Instagram, SlideShare, and Skype.

Collaborating is associated with mutual creating, testing and editing of content without location and time constraints. Tools most often used in this context are wikis, forums and discussion groups, as well as specialist/ industry related communicators. Exemplary tools include TWiki and Google Docs. 
One of the most popular functions is connecting, understood as creating a community, communicating and making contacts within the community. The channels most often used in connecting are social networks and virtual reality. In case of tools, the most important function is performed by Facebook, Linkedln, and SecondLife.

Completing is a function whose aim is to complete, describe, acquire, add or filter information, and display links between content. The most often used channels include social bookmarking, forums and discussion groups with the exemplary tools being Pinterest, FeedDemon, and Twitter.

The last function is combining, which is understood as connecting and integrating information via external channels on platforms that function as mash-ups. In this case, the most typical tool that performs the combining function is Google Maps, while other services such as Facebook or Snapchat are just starting to perform this function as well, due to their constant development.

Considering the features and complex functions of social media in image management can significantly influence the employer's brand. However, this requires appropriate competencies on the part of the company in the scope and manner of using social media in employer branding.

\section{Methodological assumptions and test resullts.}

In the first stage of the research, the author applied the method of observation known as netnography, a form of research designed to analyze cultures and online communities. (BM) The subject of the research were internet websites run by ICT industry companies, including websites and social networking sites. During the observation period, information on selected websites, as well as the degree of involvement of the surveyed enterprises in active, two-way communication with recipients, including candidates for employees, were analyzed.

The implementation of netnographic research has shown the need to deepen knowledge about the opinions and judgments of owners and managers of companies from the ICT industry regarding the use of social media aimed at creating the image of the employer. This has also become the basic goal of planned qualitative research carried out using in-depth individual interviews. Companies from the ICT industry were selected as researched entities, for whom the maintenance of creative employees and the acquisition of new talents became an important challenge. In-depth individual interviews were carried out in 10 companies with a different business profile in IT services. A partially structured research scenario was developed based on the characteristics of media functions in relation to activities related to image creation and recruitment of employees.

Table 1. The scope of using social media functions and characteristics of activities carried out by the surveyed enterprises

Roles and functions of social media

Activities of the surveyed companies in the scope of employer branding

$$
1
$$

Communicating channels: blogs, websites, All surveyed companies used Instagram to present photos describing: microblogs, forums, discussion groups, - interpersonal relationships in the organization, presentations.

Tools: YouTube, Blogger, Twitter, Instagram, SlideShare, Skype.

- friendly working conditions,

- openness and support for employees in various situations.

The actions implemented on Instagram supported the creation of image among both existing employees and potential candidates.

Several of the surveyed companies pointed to YouTube as a place for effective sharing of content in

Main goal: sharing opinion, storage and publishing content/ image, sound the form of videos referring to the employee's profile and the characteristics of the work carried out in a given organization. Videos posted on YouTube were dedicated more often to candidates and supported recruitment activities. The respondents emphasized that the attractiveness of the content conveyed had greater willingness to share the posted materials. 


\begin{tabular}{ll}
\hline \multicolumn{1}{c}{1} & \multicolumn{1}{c}{2} \\
\hline $\begin{array}{l}\text { Connecting channels: social networks, } \\
\text { virtual world. }\end{array}$ & $\begin{array}{l}\text { The companies surveyed primarily pointed out Facebook as a tool for contact with passive candidates. } \\
\text { Most of the respondents published job offers on Facebook and detailed information on the requirements } \\
\text { for candidates. Several of the respondents indicated Facebook as a platform for sharing knowledge and } \\
\text { information about various company events. } \\
\begin{array}{l}\text { Tools: Facebook, Linkedln, SecondLife, } \\
\text { World of Warcraft. }\end{array}\end{array}$ \\
$\begin{array}{ll}\text { Main goal: Forming conditions for creating to the respondents, Linkedln was mainly used to present the profiles of employees as } \\
\text { and communicating with the community }\end{array}$ & $\begin{array}{l}\text { specialists in the company. The less frequently indicated service was used to present the recruitment } \\
\text { offer }\end{array}$
\end{tabular}

Source: own study.

According to the conducted research, companies from the ICT industry notice the need to use social media in creating the employer's brand both outside and within the organization. This approach is supported by the fact that employees and candidates for employees of technology companies are representatives of Generation $\mathrm{Y}$, which declares intensive use of electronic sources in the process of job seeking.

However, it should be noted that the range of channels and tools used by the surveyed companies in relation to the functions of social media is mainly limited to communicating and connecting. The five key functions mentioned above clearly lack the tools and channels associated with collaborating. At the same time, it should be noted that the way of using tools for communication, including sharing opinions and content, is quite simple, and that there are no activities carried out on blogs, forums or discussion groups. In the case of social services such as Facebook, the involvement of the surveyed enterprises in creation of the community is too small and the care of interesting content, used to build the reach and involve online communities, is insufficient. Clearly, the Linkedln service was undervalued among the respondents. As a service for specialists and a potential place for recruiting employees, it should be an important tool for presenting recruitment offers.

Analysis of respondents' opinions seems to indicate, on the one hand, a clear need to use social media in creating the image of the employer and, on the other, a lack of sufficient skills in this area.

\section{Conclusions}

Enterprises that care about building an attractive employer brand should use social media for this purpose in the full range of functions assigned to them. Even today, too many employers still use social services as a place for presenting information, instead of getting involved in community development and active search for talents. It should be noted that the surveyed enterprises from the ICT sector treat social media in this way.

Using social media to create an employer image is especially important in the case of enterprises that employ and recruit young employees. Using channels and means of communication appropriate for Generation $\mathrm{Y}$, whose representatives form online communities and often communicate constitutes the basis for understanding the expectations, preferences and lifestyle of potential employees. In this sense, social media becomes a space where the image of the employer is verified in terms of authenticity and the degree of adaptation to the vision of the world professed by Generation Y.

Recognizing social media as a spectrum of channels and tools, as well as using it with its intended use, can facilitate the involvement of employees in the process of co-creating values in the organization. It seems that soon most companies will have to leave the comfort zone designated by what is known and move to a world in which co-participation, co-creation and open communication will determine the strength of the employer's image. In this sense, social media provides opportunities, but also sets requirements for its use. 


\section{References}

Ambler, T., Barrow, S. (1996). The employer Brand. Journal of Brand Management, 4, 185-206.

Backhaus, K., Tikoo, S. (2004). Conceptualizing and Researching Employer Branding. Career Development International, 9 (5), $501-517$.

Barrow, S., Mosley, R. (2005). The Employer Brand: Bringing the Best of Brand Management to People AT Work. Chichester: John Wiley\&Sons.

Bednarska-Olejniczak, D. (2017). Kształtowanie wizerunku pracodawcy w Internecie. Handel Wewnętrzny, 5 (370), 44-52.

Harari, O., (1998). Attracting the best minds. Management Review, 87 (4), 23-26.

Kaplan, A.M., Haenlein, M. (2010). Users of the world! The challengers and opportunities of Social Media. Business Horizons, 53 , 59-68.

Mehta, S., Sharma, S. (2016). Usage of Social Media in Employee Sourcing and its Impact in Creating an Employer Brand. Sumedha Journal of Management, 5 (4), 37-38.

Vouri, V. (2011). Social Media Changing the Competitive Intelligence Process: Elicitation of Employees' Competetitive Knowledge. Tampere: Tampere University of Technology.

Cite this article aS: Szwajlik, A. (2018). The use of social media in employer branding in the light of the research on the ICT sector enterprises. European Journal of Service Management, 4 (28/2), 493-498. DOI: 10.18276/ejsm.2018.28/2-59. 